\title{
A pilot Tuning Project-based national study on recently graduated medical students' self-assessment of competences - the TEST study
}

Pedro Grilo Diogo*, Joselina Barbosa and Maria Amélia Ferreira

\begin{abstract}
Background: The Tuning Project is an initiative funded by the European Commission that developed core competences for primary medical degrees in Europe. Students' grouped self-assessments are used for program evaluation and improvement of curricula. The TEST study aimed to assess how do Portuguese medical graduates self-assess their acquisition of core competences and experiences of contact with patients in core settings according to the Tuning framework.

Methods: Translation of the Tuning's competences (Clinical Practice - CP), Knowledge (K) items and Clinical Settings (CS) was performed. Questionnaires were created in paper and electronic formats and distributed to 1591 graduates from seven Portuguese medical schools (July 2014). Items were rated in a 6-point Likert scale (0-5) of levels of competence. Exploratory factor analysis (EFA) was conducted and Cronbach's alpha was used to evaluate the internal consistency of the questionnaire. Kruskal-Wallis and Dunn's tests were used for multiple comparisons.

Results: Three hundred eighty seven questionnaires were analyzed, corresponding to $24 \%$ of the target population. EFA yielded an 11-factor solution for CP and a 6 -factor solution for $\mathrm{K}$ items. The median value of CP factors was 2.8 ( $\mathrm{p} 25=2.0 ; \mathrm{p} 75=3.5$ ) and the median value of $\mathrm{K}$ factors was 2.6 (2.0; 3.2). Factor scores ranged from 1.3 (Legal principles) to 4.0 (Ethical principles). Clinical presentations, psychological aspects of illness, evidence-based medicine and promotion of health showed the highest results. Lower scores were detected in medical emergencies, practical procedures, prescribing drugs and legal principles. More than $90 \%$ of graduates experienced having contact with patients in 8 CS but only $24 \%$ of graduates had contact in all 14 CS. Graduates had the least contact with patients in the emergency rooms, intensive care units, palliative, rehabilitation and anesthetic care. Significant differences $(p<0.05)$ among schools were detected in 8 factors and 7 settings.

Conclusions: We developed a valid questionnaire supporting national SWOT analysis on the acquisition of core competences in medical education. Results suggest that Portuguese graduates are not fully prepared for clinical practice. Curricular improvements in core competences and the educational development of the transition period between undergraduate and postgraduate education ought to be considered. Outcome-based program evaluation relying on graduates' grouped self-assessments contributes to inform changes in medical education.
\end{abstract}

Keywords: Student grouped self-assessments, Core competences, Tuning Project, Outcome-based program evaluation, Undergraduate medical education

\footnotetext{
* Correspondence: pgrilodiogo@gmail.com

Department of Medical Education and Simulation, Faculty of Medicine

University of Porto (FMUP), Porto, Portugal
} 


\section{Background}

The basis of outcome-based education (OBE) was put forward by Tyler [1] in 1949. Instead of the educational process, OBE looks upon education with an emphasis on predetermined learning outcomes, which superintend decisions about the curricula, teaching-learning strategies and the assessment of students [2]. From 2000 onwards, OBE gained wide support and took the lead as the mainstream paradigm in the education of healthcare professionals [3].

OBE has the advantage of providing a framework for quality assurance. Outcome-based program evaluations focus on the achievement of learning outcomes at the end of specific periods of education. If outcomes are not achieved, possible problems within curricula may be detected which drive the implementation of necessary improvements [2].

Medical schools and specialist organizations have developed several sets of learning outcomes, both for undergraduate and postgraduate education [4-9]. The Tuning Project [5] is an initiative funded by the European Commission which developed learning outcomes/competences for primary medical degrees in Europe. Tuning generated learning outcomes through an iterative process of expert review after an Europe-wide internet-based survey. Tuning's core competences can assist curriculum planning or provide a framework for quality enhancement initiatives, given that they are designed to assure European standards of fitness for practice for medical graduates.

Several sources of data should be employed for a detailed analysis of medical curricula on an outcome-based paradigm. Student surveys are widely used by higher education institutions throughout the world for program evaluation purposes [10]. Although student selfassessments are acknowledged as inaccurate measures of competence at the individual level [11-13], research suggests that reliable grouped self-assessments are valid measures of the acquisition of learning outcomes by a group of students and thus important for program evaluation [14, 15]. In fact, student grouped selfassessments have guided curriculum planning [16], revisions of curricula $[17,18]$ and supported studies on graduates' preparedness for practice doctors [19-22]. Also, the Greek medical schools have developed a selfassessment questionnaire based on Tuning's core competences [23].

Nevertheless, examples of systematic outcome-based program evaluations based on student self-assessments against international sets of learning outcomes are scarce in the literature. In the Portuguese context, graduates' self-assessments right after completion of the medical course may be particularly useful for program evaluation. In fact, there is no national summative assessment in Portugal for all medical graduates blueprinted against an agreed set of learning outcomes, although Portuguese medical schools have developed learning outcomes for graduates in Medicine [24]. The purpose of the national exam to access residency is to rank medical graduates instead of assessing their clinical competence. On the other hand, schools still struggle with the development of the comprehensive and valid assessment tools. Besides a comparative study of Portuguese-speaking countries by this research group [25], no other national study has been conducted on an outcome-based paradigm.

Recent changes have been introduced in medical education in Portugal, namely the attribution of full professional autonomy to all medical graduates who complete one year of internship (the 'Ano Comum' or 'Common Year'), after which they enroll in specialty training. These changes in autonomy rules and foreseeable reforms in the Common Year and national exam highlight the need to produce research on the effectiveness of undergraduate programs in delivering core competences.

We designed the TEST study with the aim to assess whether Portuguese medical graduates perceive deficits in the acquisition of core competences and experienced of contact with patients in core clinical settings according to the Tuning framework, and whether there are significant differences among graduates from different medical schools.

\section{Methods}

This cross-sectional study was based on a survey conducted between October and December 2014. The study population included all 1591 graduates who had recently finished their medical courses in July 2014 in seven Portuguese medical schools. Graduates answered the survey before access to residency, which started in January 2015.

\section{Study instrument}

A questionnaire was created after translation of the "Tuning Project Learning Outcomes/Competences for Undergraduate Medical Education in Europe" [5].

Two researchers independently translated 12 Level 1 Tuning competences and their corresponding Level 2 competences related to Clinical Practice (70 items). Seven Knowledge domains (encompassing 39 items) and 14 Clinical Settings were also translated. Medical Professionalism outcomes were not included. A third researcher integrated both translations and created the final questionnaire, which was constituted by 123 items, including 70 Level 2 competences (Clinical Practice), 39 Knowledge items and 14 Clinical Settings.

Categorical demographic information was collected on participants' gender, age, medical school and modality of 
admission to the medical course (including General, Graduate and other contingents). Regarding Clinical Practice and Knowledge items, participants were asked to self-assess their level of competence or knowledge. A 6-point Likert scale from 0 to 5 was used $(0=$ non-existent, 1 = insufficient, 2 = sufficient, 3 = good, 4 = very good and 5 = excellent). Regarding Clinical Settings, participants were asked (yes or no question) if they had experienced contact with patients in specific learning settings (Clinical Settings were represented as CSn, being $n$ its number).

\section{Implementation and sample size}

Questionnaires were created in paper and electronic formats. Paper questionnaires were distributed by student volunteers to all graduates who attended preparation lectures for the national exam to access residency in the cities of Braga, Porto, Lisbon and Coimbra. 208 questionnaires were distributed and received. The electronic questionnaire was created in Google Forms and was diffused by e-mail through school-maintained mailing lists and through Facebook groups that are specific for medical graduates. 218 graduates filled the electronic questionnaire. Both versions of the questionnaire included an introduction to the purpose of the study. Explicit instructions for participants to fill only one of the versions of the questionnaire were given, in order to reduce the possibility of multiple responses per person. A total of 426 questionnaires were obtained.

We aimed for a sample size of five participants per item in the questionnaire (both for Clinical Practice and Knowledge components) in line with recommendations for the development of exploratory factor analysis (EFA) [26].

Questionnaires delivered back in blank or without full demographic information were excluded from analysis. We considered that the statistical analysis would likely be biased if responses to more than $10 \%$ of items were missing [27].

This study was approved by the Faculty of Medicine of the University of Porto/São João Hospital Ethics Committee, in compliance with the Helsinki Declaration. Participation was voluntary and no incentives were offered. Completion of the questionnaire constituted consent to participate. Collected data were analyzed in an anonymous way and it was not possible for the researchers to identify the participants during any phase of the study.

\section{Statistical analysis}

Data from paper questionnaires were read by a Fujitsu fi-5120c machine and entered a Microsoft Excel spreadsheet. Data from electronic questionnaires were downloaded from Google Forms into an Excel spreadsheet.
Both data were fused in an Excel spreadsheet and transported to Statistical Package for Social Sciences (SPSS) version 21.0.

The relational structure of the Clinical Practice and the Knowledge items of the questionnaire was assessed by exploratory factor analysis (EFA). Factors were extracted after main components analysis followed by an oblique rotation. The factor structure was based on the scree plot criteria, eigenvalues and percentage of variance explained. To assess the adequacy of EFA, KaiserMeyer-Olkin (KMO) and Bartlett's sphericity tests were conducted. An item was considered to belong to a certain factor when its factor load - with respect to that factor - was equal or greater than $|0.35|$, and the highest of the ones that fulfilled the previous condition. The internal consistency of the questionnaire was analyzed by Cronbach's alpha $(\alpha)$.

Factor scores were described by the median value of its items and the 25th and 75th percentiles (p25; p75). Kruskal-Wallis and Dunn tests were used for multiple comparisons of factor scores and clinical settings among medical schools. Random numbers from 1 to 7 were attributed to medical schools for the purpose of multiple comparisons.

\section{Results}

\section{Sample size and participants' characteristics}

Twenty seven percent of the study population answered the questionnaire and a sample size of $22 \%$ or more graduates was obtained in all medical schools. Sample sizes ranged from $33 \%$ (ECS-UM) to $22 \%$ (FMUL and NMS/FCM) (Table 1). 387 paper and electronic questionnaires were analyzed, after implementation of exclusion criteria. 39 paper questionnaires were excluded: ICBAS (1), FMUC (2), University of Algarve (15) and foreign schools (21).

Participants' age ranged from 23 to 40 years old. $66.9 \%$ (259) of the graduates were female and $33.1 \%$ (128) were male. In the sample, the percentage of graduates from different medical schools ranged from $20.9 \%$

Table 1 Study population and sample sizes per medical school

\begin{tabular}{lll}
\hline Medical school & Study population $^{\text {a }}$ & Sample size (\%) \\
\hline ECS-UM & 100 & $33(33)$ \\
ICBAS & 194 & $48(25)$ \\
FMUP & 242 & $70(29)$ \\
FCS-UBI & 145 & $33(23)$ \\
FMUC & 293 & $67(23)$ \\
FMUL & 371 & $81(22)$ \\
NMS/FCM & 246 & $55(22)$ \\
Total & 1591 & $387(24)$
\end{tabular}

${ }^{a}$ Number of graduated students in July 2014. Information provided by the medical schools 
(FMUL) to $8.5 \%$ (ECS-UM and FCS-UBI), in accordance to each school's number of admissions (Table 2). $85.8 \%$ (332) of graduates were admitted to medical schools by the general contingent, while $6.5 \%$ (25) were admitted by the graduate contingent and $7.0 \%$ (27) by other contingents. Cohorts of graduates from different medical schools did not differ significantly in gender, age and modality of admission ( $p>0.05$, all three cases).

Missing responses were analyzed: since the maximum absence rate response was $3.9 \%$, the values of unanswered items were replaced by the median.

\section{Statistical analysis}

Bartlett's sphericity test was statistically significant $(p<0.0001)$ for both Clinical Practice and Knowledge items, indicating that items shared a common variance. The KMO test yielded 0.926 for Clinical Practice and 0.941 for Knowledge items, suggesting that they represent more than one factor.

EFA produced an 11-factor solution for Clinical Practice and a 6-factor solution for Knowledge items (Tables 3 and 4). Clinical Practice and Knowledge factors were labeled in accordance to Tuning's descriptions. Clinical Practice factors were codified as $\mathrm{CP} n$ (being $n$ its number) and Knowledge factors were codified as $\mathrm{Kn}$.

Eleven Clinical Practice and 6 Knowledge factors explained $66.6 \%$ and $71.9 \%$ of the total variance of answers, respectively. Clinical Practice and Knowledge factors showed a global $\alpha$ of $0.971(\min \alpha=0.771-\max \alpha=0.954)$, and a global $\alpha$ of $0.965(\min \alpha=0.892-\max \alpha=0.942)$, respectively.

Table 2 Participants' characteristics

\begin{tabular}{ll}
\hline Gender & $\mathrm{N}(\%)$ \\
\hline Female & $259(66.9)$ \\
Male & $128(33.1)$ \\
Medical school ${ }^{\text {a }}$ & \\
ECS-UM & $33(8.5)$ \\
ICBAS & $48(12.4)$ \\
FMUP & $70(18.1)$ \\
FCS-UBI & $33(8.5)$ \\
FMUC & $67(17.3)$ \\
FMUL & $81(20.9)$ \\
NMS/FCM & $55(14.2)$ \\
Admission contingent ${ }^{b}$ & \\
General contingent & $332(85.8)$ \\
Graduate contingent & $25(6.5)$ \\
Other contingents & $27(7.0)$ \\
\hline a The chi-square test showed no differences between graduates from different \\
$\begin{array}{l}\text { schools in terms of gender (chi-square }=11.410, p=0.076) \text { or admission } \\
\text { contingent (chi-square }=17.733, p=0.124)\end{array}$ \\
b Three participants omitted the admission modality
\end{tabular}

The aggregation of items into factors showed 4 differences in relation to Tuning's groups of competences: 1 ) items 1 to 6 (under Level 1 'Consultation with a patient') and items 7 to 12 (under Level 1 'Clinical presentations, investigations, differential diagnoses and management plan') were aggregated into two factors (CP1 and CP2, which included, respectively, items 1, 2, 3, 7, 8 and 9, and items 4, 5, 6, 10, 11 and 12), 2) six items under Level 1 'Ethical and Legal principles in medical practice' represented two separate factors (CP7-Ethical principles and CP8-Legal principles), 3) three Level 1 competences ('Principles, skills and knowledge of evidence-based medicine, 'Information and information technology effectively in a medical context' and 'Scientific principles, method and knowledge to medical practice') were combined in a single factor (CP10) and 4) two Knowledge domains ('Basic Sciences' and 'Clinical Sciences') produced a single factor (K1).

\section{Factor scores}

The median value of Clinical Practice (CP) factors was 2.8 (p25 = 2.0; p75 = 3.5) and the median value of Knowledge $(\mathrm{K})$ factors was $2.6(2.0 ; 3.2)$ in a scale from 0 to 5.

$\mathrm{CP}$ factor scores ranged from 1.3 (CP8: Legal principles) to 4.0 (CP7: Ethical principles), which correspond, respectively, to insufficient and very good levels of competence. $\mathrm{K}$ factor scores ranged from 2.0 (K6: Role in health care systems) to 3.0 (K4: Public Health and K5Ethical principles), corresponding to good levels of competence (Figs. 1 and 2).

Factors CP1, CP7, CP10, CP11, K1, K2, K4 and K5 scored above the respective $\mathrm{CP}$ or $\mathrm{K}$ median value while factors CP2, CP3, CP4, CP5, CP8, K3 and K6 scored below the median values.

CP6 (Communicate in medical context) equaled the $\mathrm{CP}$ median value. Results from the items aggregated in this factor ranged from 2.58 and 2.63 ("communicate with disabled people" and "communicate in breaking bad news") to 4.00 ("communicating with patients" or "communicating with colleagues").

Graduates self-assessed their competence as very good in CP7 and CP10. Good levels of competence were perceived in the majority of factors. Sufficient levels of competence were shown in CP3, CP4, CP5, K3 and K6. An insufficient level of competence was obtained in CP8 (Table 5).

The lowest scored items of the questionnaire were found in medical emergencies, practical procedures and legal principles:

- 'Medical emergencies' included "trauma care according to guidelines" (1.59), "advanced life support according to guidelines" (1.72) and "treating medical emergencies" (2.04). 
Table 3 Exploratory factor analysis results for Clinical Practice factors

\begin{tabular}{|c|c|c|c|c|c|c|}
\hline Factors & Label & $\mathrm{N}^{\mathrm{a}}$ & Loadings (min, max) & Eigenvalue & Variance explained (\%) & a \\
\hline CP1 & Clinical presentations and diagnosis & 6 & $0.463,0.646$ & 1.8 & 2.7 & 0.851 \\
\hline CP2 & Consultation and management plan & 6 & $0.535,0.707$ & 2.4 & 3.7 & 0.868 \\
\hline CP3 & Medical emergencies & 6 & $0.502,0.834$ & 2.0 & 3.0 & 0.901 \\
\hline CP4 & Prescribe drugs & 3 & $0.779,0.800$ & 1.4 & 2.1 & 0.890 \\
\hline CP5 & Practical procedures & 11 & $0.350,0.829$ & 21.7 & 32.8 & 0.910 \\
\hline CP6 & Communication in medical context & 10 & $0.469,0.650$ & 2.5 & 3.7 & 0.908 \\
\hline CP7 & Ethical principles & 3 & $0.607,0.652$ & 1.2 & 1.8 & 0.771 \\
\hline CP8 & Legal principles & 3 & $0.627,0.746$ & 1.5 & 2.3 & 0.839 \\
\hline CP9 & Psychological and social aspects of illness & 3 & $0.697,0.744$ & 1.2 & 1.9 & 0.954 \\
\hline CP10 & Evidence-based medicine, technology and science & 8 & $0.401,0.874$ & 4.6 & 7.0 & 0.910 \\
\hline CP11 & Population health and health care system & 7 & $0.517,0.721$ & 3.7 & 5.6 & 0.904 \\
\hline
\end{tabular}

${ }^{a}$ Total number of items. Clinical Practice items number 22, 23 and 55 were removed since the internal reliability of the respective factors increased with their exclusion; item 35 was removed because of its low factor load (0.30)

- 'Practical procedures' showed low scores in "performing blood transfusions" (0.82), "intravenous therapy and using infusion devices" (1.47), "urinary catheterization" (1.50), "basic respiratory tests" (1.77) and "venous catheterization" (1.80). The highest scored items are "administering oxygen" (3.04), "urinalysis" (2.65), "blood pressure measurement" (2.64), "suturing" (2.61) and "move and handle patients" (2.60).

- CP factor 'Prescribe drugs' showed low scores in "prescribing in a clear and precise way" (2.14), "associating medications" (2.19) and "reviewing the adequacy of drug" therapy (2.40). The related $\mathrm{K}$ factor 'Drugs and prescription' included items "drug interactions" (2.43), "pharmacokinetics and pharmacodynamics" (2.35), "utilization of blood transfusions and blood products" (2.10) and "complementary/alternative medicine" (1.95).

- CP factor 'Legal principles' included very poorly scored items such as "certifying deaths" (1.64), "applying national and European legislation to healthcare" (1.64) and "requiring autopsies" (1.06). The equivalent $\mathrm{K}$ factor 'Role in healthcare systems' included items such as "relevant legislation for medical practice" (2.32), "principles of clinical audit"
(2.26), "knowledge about healthcare systems" (2.10) and "professional regulation systems" (1.77).

Factor scores were compared among medical schools. Multiple comparisons highlighted significant differences $(p<0.05)$ in factors CP1, CP3, CP5, CP6, CP8, CP10, K2 and $\mathrm{K} 5$. CP7 was the highest and CP8 the lowest scored factor in all medical schools (Figs. 3 and 4).

\section{Clinical Settings}

More than $90 \%$ of graduates experienced having contact with patients in Clinical Settings CS2, CS3, CS4, CS5, CS6, CS8, CS9 and CS11. Conversely, CS13 (47 \%), CS12 (59 \%) and CS7 (60 \%) showed the lowest percentages (Table 6). Only $24 \%$ of graduates had contact with patients in all 14 Clinical Settings.

Graduates from different medical schools showed average percentages of contact with patients (considering all 14 Clinical Settings) ranging from $75 \%$ (school 2) to $91 \%$ (school 4). Considering specific settings, percentages varied from $23 \%$ (CS13, school 2) to $100 \%$ (several examples in different schools). Multiple comparisons showed significant differences $(p<0.05)$ among graduates from different schools in 7 settings (CS1, CS7, CS10, CS11, CS12, CS13, CS14) (Fig. 5).

Table 4 Exploratory factor analysis results for Knowledge factors

\begin{tabular}{|c|c|c|c|c|c|c|}
\hline Factors & Label & $\mathrm{N}^{\mathrm{a}}$ & Loadings (min, max) & Eigenvalue & Variance explained (\%) & $a$ \\
\hline$\overline{\mathrm{K} 1}$ & Basic and clinical sciences & 11 & $0.577,0.820$ & 16.3 & 41.7 & 0.929 \\
\hline K2 & Behavioural and social sciences & 3 & $0.740,0.807$ & 1.4 & 3.6 & 0.892 \\
\hline K3 & Drugs and prescribing & 8 & $0.488,0.806$ & 2.2 & 5.5 & 0.928 \\
\hline K4 & Public Health & 10 & $0.442,0.872$ & 4.4 & 11.2 & 0.919 \\
\hline K5 & Ethical principles & 3 & $0.633,0.735$ & 1.3 & 3.3 & 0.919 \\
\hline K6 & Role in healthcare systems & 4 & $0.728,0.793$ & 2.6 & 6.6 & 0.942 \\
\hline
\end{tabular}

\footnotetext{
${ }^{a}$ Total number of items. No items were excluded
} 


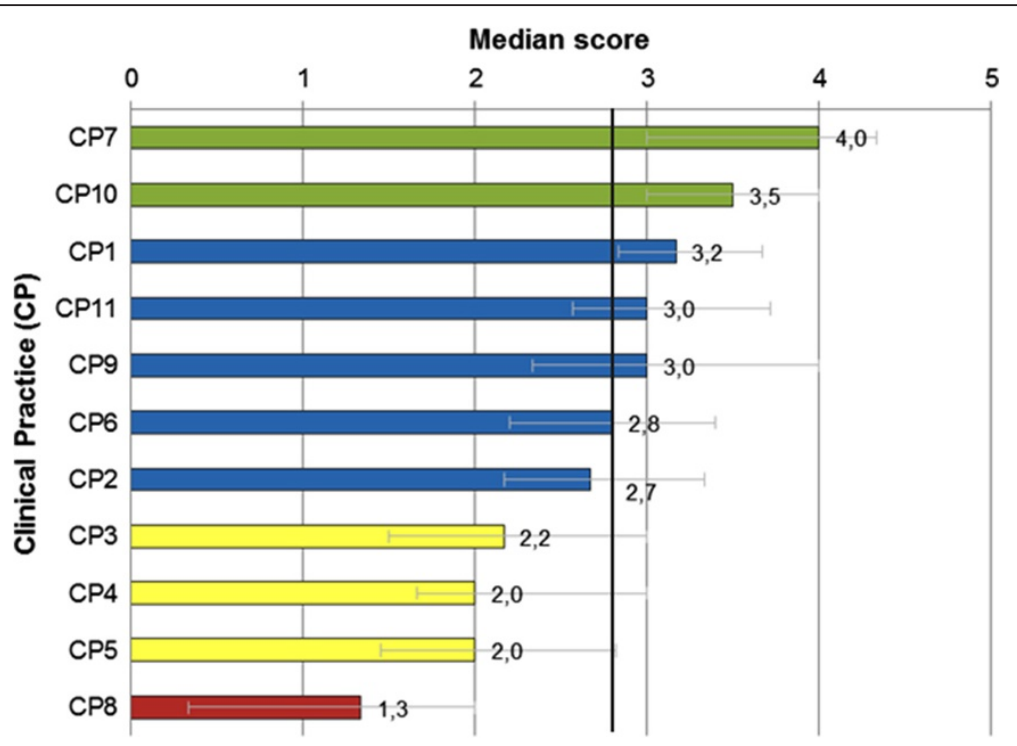

Fig. 1 Clinical Practice factor scores. The error bars represent the interquartile range (p25-p75). Colors represent levels of competence: green bars (very good), blue (good), yellow (sufficient), red (insufficient). The vertical line corresponds to the median score of all Clinical Practice factors (2.8)

\section{Discussion}

We have validated a questionnaire that can serve as a SWOT analysis tool for medical education at a national level. In fact, the TEST study provides a pioneer input on Portuguese medical graduates' self-assessed clinical competence against an European referential. For the first time, the effectiveness of Portuguese medical schools in delivering core competences and exposing students to core clinical settings is explored, and areas where curricula may benefit from improvements are highlighted.

\section{How did graduates self-assess their acquisition of core competences?}

The median values of Clinical Practice and Knowledge factors correspond to a level of self-assessed competence between sufficient and good. The majority of factors showed a good level of competence. Important differences were found among $\mathrm{CP}$ factors, scores ranged from
1.3 (insufficient) to 4.0 (very good) in a 0 to 5 Likert scale. Among $\mathrm{K}$ factors, variation was not that evident (from 2.0 to 3.0). Furthermore, CP factors also showed the highest and the lowest scored items in the questionnaire. These results show that the dispersion of results was greater in $\mathrm{CP}$ competences.

Important aspects of medical practice were selfassessed above the median $\mathrm{CP}$ value in all medical schools: "Consultation with a patient and management plan", "Ethical principles", "Psychological and social aspects of illness", "Evidence-based medicine and scientific principles", as well as "Population health and healthcare system". Knowledge on "Public Health" was also scored above the median $\mathrm{K}$ value in all schools.

On the other hand, CP factors "Medical emergencies", "Practical procedures", "Prescribe drugs" and "Legal principles" scored below the median $\mathrm{CP}$ value in all medical schools. These results are consistent with other

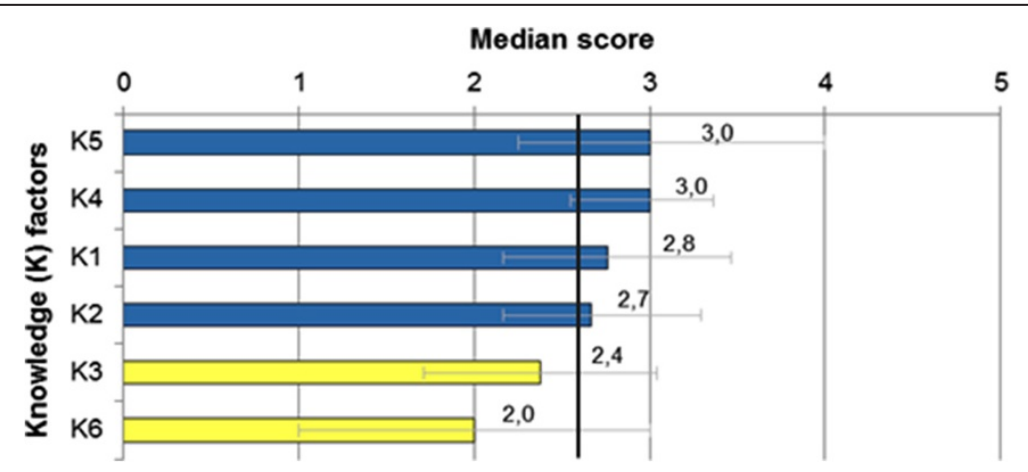

Fig. 2 Knowledge factor scores. The error bars represent the interquartile range (p25-p75). Colored bars represent levels of competence: blue (good) and yellow (sufficient). The vertical line corresponds to the median score of all Knowledge factors (2.6) 
Table $\mathbf{5}$ Levels of self-assessed competence in Clinical Practice and Knowledge factors

\begin{tabular}{|c|c|c|}
\hline Factor and label & $\begin{array}{l}\text { Median } \\
\text { value }^{a}\end{array}$ & $\begin{array}{l}\text { Levels of } \\
\text { competence }\end{array}$ \\
\hline CP7 - Ethical principles & 4.0 & \multirow{2}{*}{$\begin{array}{l}\text { Very good } \\
\text { (3.5 to } 5.0)\end{array}$} \\
\hline $\begin{array}{c}\text { CP10 - Evidence-based medicine, } \\
\text { technology and science }\end{array}$ & 3.5 & \\
\hline $\begin{array}{l}\text { CP1 - Clinical presentations and } \\
\text { diagnosis }\end{array}$ & 3.2 & \multirow[t]{9}{*}{ Good (2.5 to $<3.5)$} \\
\hline $\begin{array}{l}\text { CP9 - Psychological and social aspects } \\
\text { of illness }\end{array}$ & 3.0 & \\
\hline $\begin{array}{l}\text { CP11 - Population health and health } \\
\text { care system }\end{array}$ & 3.0 & \\
\hline K4 - Public health & 3.0 & \\
\hline K5 - Ethical principles & 3.0 & \\
\hline $\begin{array}{l}\text { CP6 - Communication in medical } \\
\text { context }\end{array}$ & 2.8 & \\
\hline K1 - Basic and clinical sciences & 2.8 & \\
\hline $\begin{array}{l}\text { CP2 - Consultation and management } \\
\text { plan }\end{array}$ & 2.7 & \\
\hline K2 - Behavioural and social sciences & 2.7 & \\
\hline K3 - Drugs and prescribing & 2.4 & \multirow{5}{*}{$\begin{array}{l}\text { Sufficient } \\
(1.5 \text { to }<2.5)\end{array}$} \\
\hline CP3 - Medical emergencies & 2.2 & \\
\hline $\begin{array}{l}\text { K6 - Role of the doctor in healthcare } \\
\text { systems }\end{array}$ & 2.0 & \\
\hline CP5 - Practical procedures & 2.0 & \\
\hline CP4 - Prescribe drugs & 2.0 & \\
\hline CP8 - Legal principles & 1.3 & $\begin{array}{l}\text { Insufficient } \\
(0.0 \text { to }<1.5)\end{array}$ \\
\hline
\end{tabular}

${ }^{a}$ 6-point Likert scale (0-5) studies on self-assessed competence in recent graduates or junior doctors [28, 29].

Poor grouped self-assessments in "Medical emergencies" might be explained graduates' feelings of incapacity to deal with emergent clinical scenarios, fear of making mistakes and limited opportunities for practice in emergency settings during the medical courses. Regarding "Practical procedures", low self-assessment scores may reflect the same needs of improvement in medical curricula, namely more opportunities for practice in simulated and real patients.

In what refers to the prescription of drugs, Clinical Practice (Prescribe drugs) and Knowledge (Drugs and prescription) factors were coherent, which suggests internal consistency of the questionnaire and emphasizes low self-assessed competence in this domain. These results may reflect the lack of practical or case-based teaching approaches to therapeutics which could be more adequate for transition to postgraduate training than the frequently undertaken theoretical approaches.

Competence on "Legal principles" in medical practice was very poorly scored by recent graduates. Both the Clinical Practice (CP8) and the equivalent Knowledge (K6) factor on that domain showed that graduates are not familiar with relevant legislation and medical paperwork/administrative tasks.

All the above-mentioned domains of clinical competence are required of Portuguese medical graduates in order to provide quality patient care, notwithstanding that they are under supervision and integrated in medical teams. The follow-up on recent graduates through the 'Common Year' and residency would clarify whether these self-assessed deficits in the development of clinical

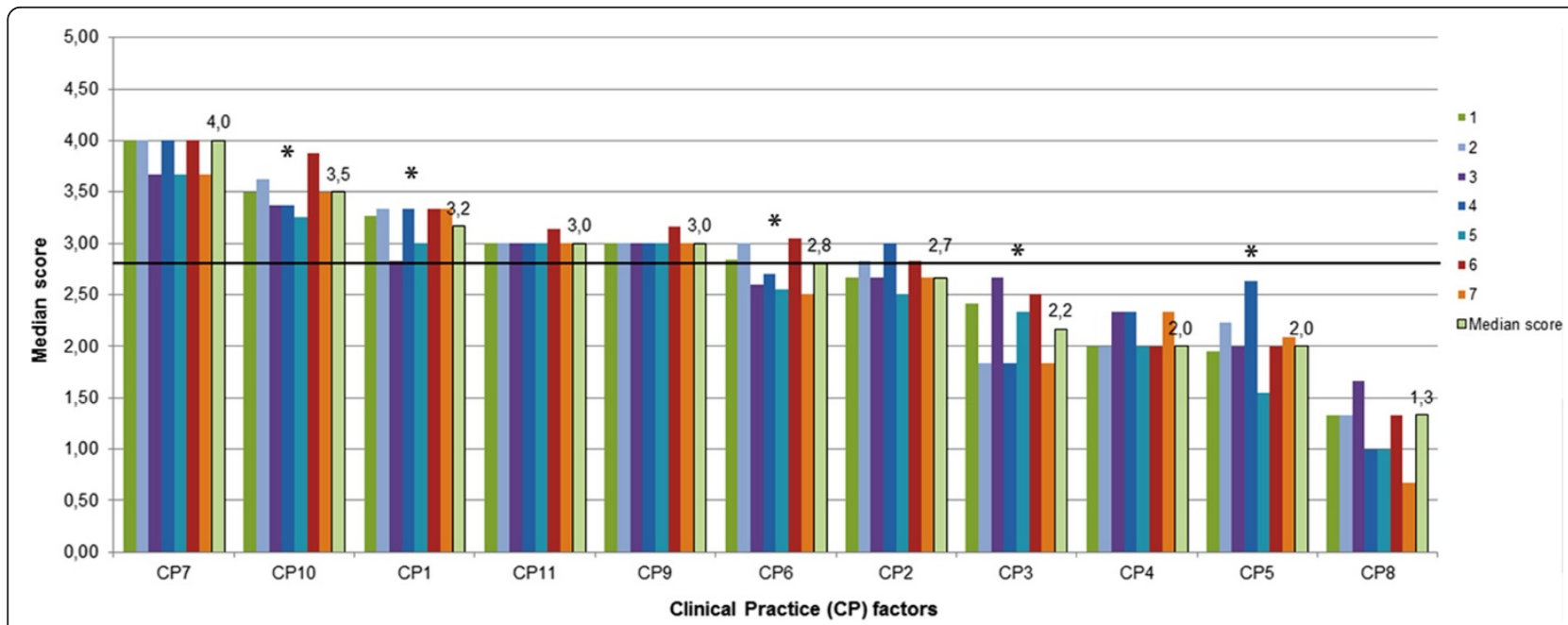

Fig. 3 Clinical Practice factor scores per medical school. Random numbers from 1 to 7 were attributed to different schools. The horizontal line shows the median value of Clinical Practice factors (2.8). ${ }^{*}$ significant differences among schools $(p<0.05)$ 


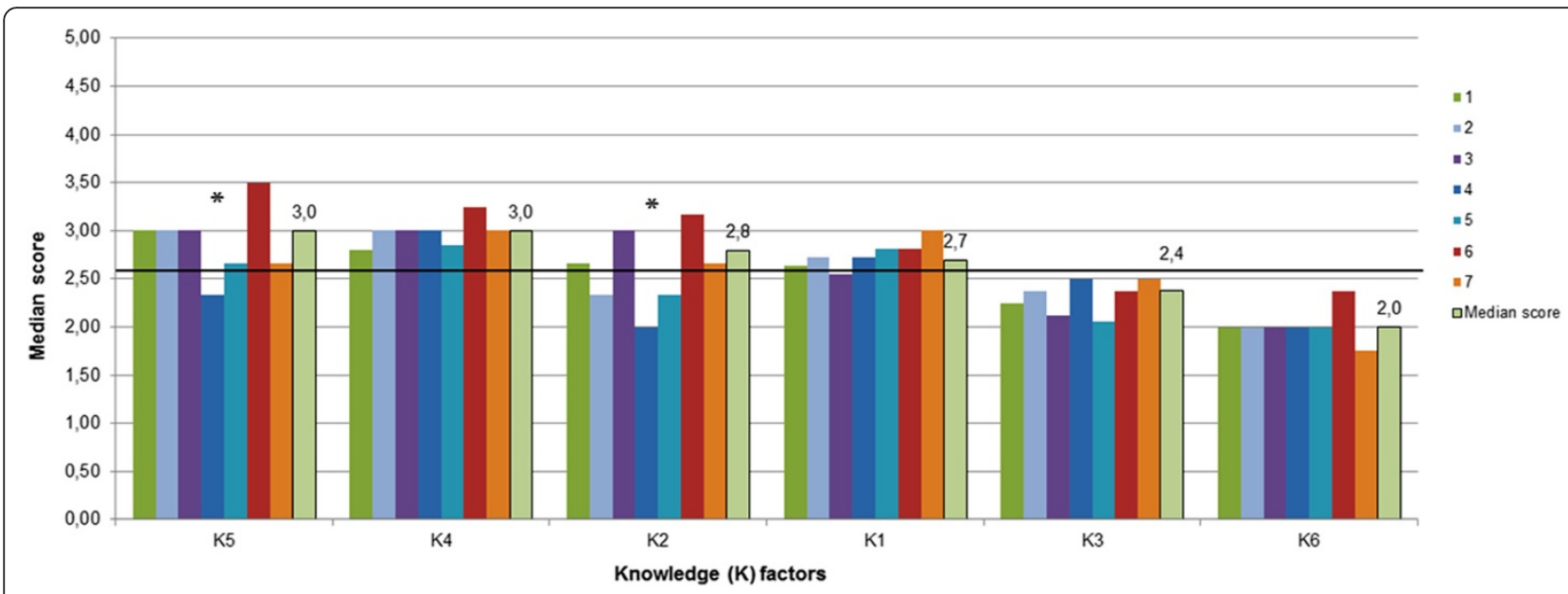

Fig. 4 Knowledge factor scores per medical school. Random numbers from 1 to 7 were attributed to different schools. The horizontal line shows the median value of Knowledge factors (2.6). * significant differences among schools $(p<0.05)$

competence are maintained or improved, provide more information for undergraduate program evaluation and might show latent insufficiencies in clinical competence. This longitudinal approach has been followed in the United Kingdom, where research used quantitative and qualitative methods such as interviews of graduates,

Table 6 Percentage of graduates who experienced having contact with patients in core Clinical Settings (in descending order)

\begin{tabular}{ll}
\hline Clinical settings & N (\%) \\
\hline $\begin{array}{l}\text { CS2 - Care of general (internal) medical patients } \\
\text { in medical admission units }\end{array}$ & $377(99)$ \\
$\begin{array}{l}\text { CS4 - Care in the community/family practice/primary } \\
\text { care }\end{array}$ & $377(99)$ \\
CS3 - Care of general surgical patients in surgical & $375(98)$ \\
admission units & \\
CS5 - Care for elderly patients & $372(98)$ \\
CS6 - Care for sick children & $370(97)$ \\
CS9 - Obstetric and gynaecological care & $370(97)$ \\
CS8 - Care for mentally ill patients & $365(96)$ \\
CS11 - Care of patients with specialized medical \\
Conditions (eg haematology, renal) \\
CS14 - Care of patients with specialized surgical \\
Conditions (eg cardiac surgery, urology) \\
CS1 - Care of acutely ill patients in Casualty/Accident \\
and Emergency units \\
CS10 - Care for critically ill patients in Intensive Care Units \\
CS7 - Care for the dying, palliative care \\
CS12 - Anaesthetic care & $273(71)$ \\
CS13 - Rehabilitation medicine & $230(60)$ \\
\hline
\end{tabular}

their colleagues, senior doctors and other healthcare professionals [28].

\section{Did graduates experience contact with patients in core clinical settings?}

The vast majority of graduates experienced contact with patients in most of the core clinical settings, including internal medicine and surgery admission units, primary care, care of elderly patients, children, pregnant women and psychiatric patients.

Nevertheless, around one quarter of graduates did not have contact with acutely ill patients in emergency or intensive care units, which may link to the above-mentioned results of lower self-assessed competence regarding "Medical emergencies". This is also consistent with studies on first-year residents [20]. Percentages of graduates who had contact with patients in other settings may also unveil deficiencies in undergraduate education: only $40 \%$ of graduates experienced contact in palliative and anesthetic care. In fact, the item "providing care of the dying and their families" (2.08) was the lowest scored of its factor, which shows consistency in the study's findings.

Clinical Settings with the lowest percentages might be underused for learning purposes during undergraduate education, which may impact on graduates' preparation and confidence to deal with specific types of patients and healthcare needs.

However, we point out that the questionnaire did not evaluate the quality or quantity of the learning experiences in clinical settings. Further research may show other settings in which learning experiences were not frequent and/or did not have positive educational value, 


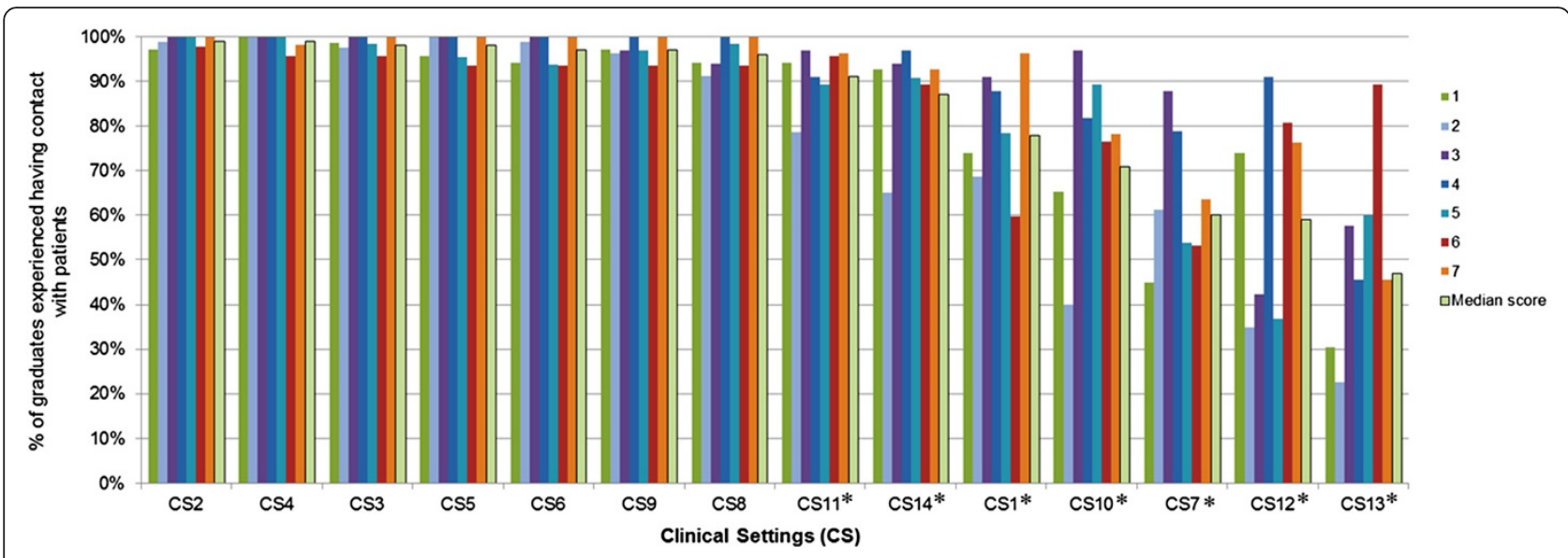

Fig. 5 Percentage of graduates who experienced having contact with patients in core Clinical Settings per medical school. * significant differences between schools $(p<0.05)$

thus contributing to lower clinical competence among medical graduates.

\section{Are there differences between graduates from different medical schools?}

We found that the highest and lowest scored factors were common among cohorts of graduates from different Portuguese medical schools. In fact, no single school or groups of schools showed consistently high or consistently low results across the various parts of this study. Differences among schools were smaller than differences among different clinical competences, knowledge domains and clinical settings. This conclusion was also obtained in previous studies on the effectiveness of medical undergraduate programs in the United Kingdom [28]. This may indicate that the school effect is less important than the effect of high-quality clinical experiences in specific disciplines or active learning behaviours.

Nevertheless, significant differences among medical schools were found in some $\mathrm{CP}$ and $\mathrm{K}$ factors: school 6 scored the highest in 4 out of $6 \mathrm{~K}$ factors. Importantly, differences among schools with regard to percentages of contact with patients in some Clinical Settings are sometimes substantial, namely in the settings with the lowest percentages, such as emergency and intensive care units, palliative care, anesthetic care, rehabilitation medicine and specialized surgical and medical conditions: for example, while $89.4 \%$ of graduates from school 7 had contact with patients in rehabilitation units, only $22.5 \%$ of graduates from school 3 had the same learning opportunities (in fact, school 3 showed the lowest percentages in 4 out of 14 Clinical Settings).

Differences among schools may be explained by an analysis of differences in their medical curricula, teaching-learning strategies or even assessment methods.
Regarding Clinical Settings, differences may reveal that only some medical schools have acknowledged the importance of all the Tuning core clinical settings in undergraduate education. Marked differences among schools can also be influenced by the available healthcare units and the collaboration with teaching hospitals.

We found that Portuguese medical schools may not be considerably different with regard to their effectiveness in delivering core competences, but this requires further research. In fact, comparative research may lead to substantial progress in medical education [30]. Outcomebased program evaluations might stimulate faculty development, guide recently established medical schools [21] and strengthen schools' accountability as elements of larger healthcare systems. Medical schools' collaborative efforts for program evaluation and detection of areas needing improvement in undergraduate education have been developed, which included recent graduates' selfassessments [28].

\section{Limitations}

The TEST study analyzed recent medical graduates' grouped self-assessment of core competences in order to infer about real clinical competence and consequently about the effectiveness of undergraduate programs. This emphasizes the need to interpret results with care, considering beforehand some relevant topics.

We consider that our sample size is representative of the study population. In fact, almost one out of four Portuguese medical graduates answered the survey which fulfilled our aim of five participants per item for the purpose of factor analysis - and the sample closely resembles the population in terms of gender, age and admission contingent. Also, medical schools are represented in the sample in accordance to their number of admissions, and 
cohorts of graduates from different schools were not different in terms of gender, age or modality of admission.

Questionnaires were implemented in preparation lectures for the national exam to access residency, which might have induced a selection bias that favored more interested students or, conversely, students that need improvement. Moreover, the possibility of more than one response to the survey per person needs to be considered, since paper and electronic versions of the questionnaire were distributed. However, explicit indications were given so that only one version of the questionnaire was filled and we have no reasons to believe that a selection bias had a significant impact in the study.

The final year of the medical course (which graduates had completed in July) might have had considerable impact on graduates' self-assessments. Hence, the study's findings may be more reflective of the later stages of medical curricula, especially clinical experiences in the final year. This suggests that the lowest scored factors highlight areas of clinical competence and knowledge that might be improved by the educational development of the transition period between undergraduate and postgraduate training. In fact, the final year of the medical course in Portugal shows some of the problems pointed out in the literature [31].

Regarding the study instrument, Tuning core outcomes are reassuring in terms of content validity and the exploratory factor analysis yielded meaningful factors that explained a great proportion of the variance of answers. Nevertheless, concerns regarding the questionnaire's face validity may be raised. We used a 6-point Likert scale of levels of competence (from non-existent to excellent competence) in which graduates had to define what "sufficient" competence meant, for each item of questionnaire. The concept of "sufficient competence" may be difficult to define and interpreted differently among graduates. Also, they may have different interpretations of the concept depending on their medical school, since learning outcomes, curricula, learning and assessment experiences might have influenced their expectations and standards. These limitations may harm the validity of comparisons among schools. A non-differential bias may also explain why only one of the factors (CP8) was self-assessed below a sufficient level of competence; in order to obtain a clearer view on the highest and lowest areas of self-assessed competence, we interpreted factor scores considering their absolute scores and their position in relation to the median value of all Clinical Practice or Knowledge factors. Narrative descriptions might improve the questionnaire's face validity by associating each level of competence in each item to specific clinical scenarios.
Importantly, competence on practical procedures seems to be more accurately self-assessed than knowledge [32]. Also, the focus on medical knowledge is reduced at later stages of the medical courses in Portugal. Graduates may therefore have more difficulties to self-assess their knowledge than their competence in procedural skills, which leads us to consider that this study's findings regarding Clinical Practice factors show a better correlation with Portuguese graduates' real competence and prospective difficulties in the 'Common Year'.

Grouped self-assessments are particularly important for program evaluation in the Portuguese context, where it is difficult to define an objective measure of clinical competence which can be considered the gold-standard at a national level. Also, research based on grouped self-assessments is inexpensive and stimulates graduate's self-reflection and engagement in medical education. In fact, the purpose of this study is not to obtain a precise measurement of individual or even group competence, but to provide important data for the purpose of evaluating program effectiveness and driving outcome-based curricular improvement. We believe that results regarding core clinical competences with the lowest self-assessed scores are the most relevant for program evaluation purposes and deserve more attention from medical schools. Further research may refine this pilot initiative, emphasizing domains of clinical competence which are more prone to deliver valid grouped self-assessment data, and improving the survey's implementation in collaboration with all Portuguese medical schools.

\section{Conclusion}

The TEST study developed a valid and sensitive questionnaire that supports national SWOT analysis on the acquisition of core competences in undergraduate medical education. In fact, graduates' self-assessments highlighted deficits in core clinical competences at a national level. Results suggest that Portuguese graduates are not fully prepared for clinical practice according to the Tuning Project's European referential. Medical emergencies, practical procedures, prescribe drugs and legal principles in medical practice showed the lowest self-assessment scores. Graduates had the least contact with patients in the emergency rooms, intensive care units, palliative, rehabilitation and anesthetic care. Cohorts of graduates are similar among medical schools, revealing mostly the same stronger and weaker domains of self-assessed competence and knowledge. Curricular improvements in the above-mentioned areas and the educational development of the transition period between undergraduate and postgraduate education ought to be considered. 
The TEST study supports the idea that outcomebased program evaluations, relying on graduates' grouped self-assessments, can contribute to inform changes in medical education at a national level.

\section{Abbreviations}

ECS-UM: Escola de Ciências da Saúde da Universidade do Minho (School of Health Sciences - University of Minho, Braga); EFA: Exploratory factor analysis; FCS-UBI: Faculdade de Ciências da Saúde da Universidade da Beira Interior (Faculty of Health Sciences - University of Beira Interior, Covilhã); FMUC: Faculdade de Medicina da Universidade de Coimbra (Faculty of Medicine - University of Coimbra); FMUL: Faculdade de Medicina da Universidade de Lisboa (Faculty of Medicine - University of Lisbon); FMUP: Faculdade de Medicina da Universidade do Porto (Faculty of Medicine - Unversity of Porto); ICBAS: Instituto de Ciências Biomédicas Abel Salazar (Institute of Biomedical Sciences Abel Salazar - University of Porto); KMO: Kaiser-Meyer-Olkin; NMS/FCM: NOVA Medical School; OBE: Outcomebased education; SPSS: Statistical Package for Social Sciences; SWOT: Strengths, Weaknesses, Opportunities and Threats.

\section{Competing interests}

The authors declare that they have no competing interests. The authors alone are responsible for the content and writing of this article.

\section{Authors' contributions}

PGD designed the study and drafted the manuscript. JB performed the statistical analysis. MAF coordinated the research and made a critical review of the manuscript. All authors read and approved the final manuscript.

\section{Authors' information}

PGD is a recent medical graduate with special interest in Medical Education. $\mathrm{He}$ is researcher at the Department of Medical Education and Simulation at the Faculty of Medicine of the University of Porto. JB is researcher at the Department of Medical Education and Simulation at the Faculty of Medicine of the University of Porto, graduate in Mathematics Applied to Technology. She attends the PhD Program in Biomedicine. MAF is Dean of the Faculty of Medicine of the University of Porto and former Head of the Department of Medical Education and Simulation.

\section{Acknowledgements}

The authors acknowledge the important work conducted by student and graduate volunteers in the implementation of questionnaires across medical schools.

Received: 10 April 2015 Accepted: 15 December 2015 Published online: 19 December 2015

\section{References}

1. Ralph TW. Basic principles of curriculum and instruction. Chicago: University of Chicago Press; 1949.

2. Harden JR, Crosby MH, Davis M, Friedman RM. AMEE Guide No. 14: Outcome-based education: Part 5-From competency to meta-competency: a model for the specification of learning outcomes. Med Teach. 1999;21(6): 546-52. doi:10.1080/01421599978951.

3. Frank JR, Snell LS, Cate OT, Holmboe ES, Carraccio C, Swing SR, et al. Competency-based medical education: theory to practice. Med Teach. 2010; 32(8):638-45. doi:10.3109/0142159x.2010.501190

4. Bloch $R$, Burgi $H$. The Swiss catalogue of learning objectives. Med Teach. 2002;24(2):144-50. doi:10.1080/01421590220120759.

5. Cumming A, Ross M. The Tuning Project for Medicine-learning outcomes for undergraduate medical education in Europe. Med Teach. 2007;29(7): 636-41. doi:10.1080/01421590701721721.

6. Frank JR, Danoff D. The CanMEDS initiative: implementing an outcomesbased framework of physician competencies. Med Teach. 2007;29(7):642-7. doi:10.1080/01421590701746983.

7. Stern DT, Ben-David MF, De Champlain A, Hodges B, Wojtczak A, Schwarz MR. Ensuring global standards for medical graduates: a pilot study of international standard-setting. Med Teach. 2005;27(3):207-13. doi:10.1080/ 01421590500129571
8. Swing SR. The ACGME outcome project: retrospective and prospective. Med Teach. 2007;29(7):648-54. doi:10.1080/01421590701392903.

9. GMC. Tomorrow's doctors. London: GMC; 2009.

10. Richardson JTE. Instruments for obtaining student feedback: a review of the literature. Assess Eval High Educ. 2005;30(4):387-415. doi:10.1080/ 02602930500099193.

11. Gordon MJ. A review of the validity and accuracy of self-assessments in health professions training. Acad Med. 1991;66(12):762-9.

12. Eva KW, Regehr G. Knowing when to look it up: a new conception of selfassessment ability. Acad Med. 2007;82(10 Suppl):S81-4. doi:10.1097/ACM. Ob013e31813e6755

13. Stewart J, O'Halloran C, Barton JR, Singleton SJ, Harrigan P, Spencer J. Clarifying the concepts of confidence and competence to produce appropriate self-evaluation measurement scales. Med Educ 2000:34(11):903-9.

14. Peterson LN, Eva KW, Rusticus SA, Lovato CY. The readiness for clerkship survey: can self-assessment data be used to evaluate program effectiveness? Acad Med. 2012;87(10):1355-60. doi:10.1097/ACM. ob013e3182676c76

15. D'Eon MF, Trinder K. Evidence for the validity of grouped self-assessments in measuring the outcomes of educational programs. Eval Health Prof. 2014 37(4):457-69. doi:10.1177/0163278713475868.

16. Clack GB. Medical graduates evaluate the effectiveness of their education. Med Educ. 1994;28(5):418-31.

17. Raupach T, Munscher C, Beissbarth T, Burckhardt G, Pukrop T. Towards outcome-based programme evaluation: using student comparative selfassessments to determine teaching effectiveness. Med Teach. 2011;33(8): e446-53 doi:10.3109/0142159x2011.586751.

18. Gibson KA, Boyle P, Black DA, Cunningham M, Grimm MC, McNeil HP. Enhancing evaluation in an undergraduate medical education program. Acad Med. 2008;83(8):787-93. doi:10.1097/ACM.0b013e31817eb8ab.

19. Goldacre MJ, Lambert T, Evans J, Turner G. Preregistration house officers' views on whether their experience at medical school prepared them well for their jobs: national questionnaire survey. BMJ. 2003;326(7397):1011-2. doi:10.1136/bmj.326.7397.1011

20. Goldacre MJ, Taylor K, Lambert TW. Views of junior doctors about whethe their medical school prepared them well for work: questionnaire surveys. BMC Med Educ. 2010;10:78. doi:10.1186/1472-6920-10-78.

21. Bleakley A, Brennan N. Does undergraduate curriculum design make a difference to readiness to practice as a junior doctor? Med Teach. 2011; 33(6):459-67. doi:10.3109/0142159x.2010.540267.

22. Ochsmann EB, Zier U, Drexler H, Schmid K. Well prepared for work? Junior doctors' self-assessment after medical education. BMC Med Educ. 2011;11: 99. doi:10.1186/1472-6920-11-99.

23. Dimoliatis I, Lyrakos G, Tseretopoulou X, Tzamalis T, Benos A, Gogos C, et al. Development and validation of the 'iCAN!' - a self-administered questionnaire measuring outcomes/ competences and professionalism of medical graduates. Universal J Educ Res. 2014;2:19-36. doi:10.13189/ujer. 2014.020103.

24. Victorino RJC, McKim J. Licenciado Médico em Portugal. Core Graduates Learning Outcomes Project. 2005.

25. Barbosa J, Severo M, Fresta M, Ismail M, Ferreira MA, Barros H. How students perceive medical competences: a cross-cultural study between the medical course in Portugal and African Portuguese speaking countries. BMC Med Educ. 2011;11:24. doi:10.1186/1472-6920-11-24.

26. Tanaka JS. "How Big Is Big Enough?": sample size and goodness of fit in structural equation models with latent variables. Child Dev. 1987;58(1):13446. doi:10.2307/1130296.

27. Bennett DA. How can I deal with missing data in my study? Aust N Z J Public Health. 2001:25(5):464-9.

28. Illing J, Morrow G, Kergon C, Burford B, Spencer J, Peile E et al. How prepared are medical graduates to begin practice ? a comparison of three diverse UK medical schools. Final report to GMC April 2008. Project Report: DU2008.

29. Monrouxe L, Bullock A, Cole J, Gormley G, Kaufhold K, Kelly N et al. How Prepared are UK Medical Graduates for Practice? Final report from a programme of research commissioned by the General Medical Council. Gen Med Counc. 2014

30. Cook DA. If you teach them, they will learn: why medical education needs comparative effectiveness research. Adv Health Sci Educ Theory Pract. 2012 17(3):305-10. doi:10.1007/s10459-012-9381-0. 
31. Walling A, Merando A. The fourth year of medical education: a literature review. Acad Med. 2010;85(11):1698-704. doi:10.1097/ACM. 0b013e3181f52dc6.

32. Colthart I, Bagnall G, Evans A, Allbutt H, Haig A, Illing J, et al. The effectiveness of self-assessment on the identification of learner needs, learner activity, and impact on clinical practice: BEME Guide no. 10. Med Teach. 2008;30(2):124-45. doi:10.1080/01421590701881699.

Submit your next manuscript to BioMed Central and we will help you at every step:

- We accept pre-submission inquiries

- Our selector tool helps you to find the most relevant journal

- We provide round the clock customer support

- Convenient online submission

- Thorough peer review

- Inclusion in PubMed and all major indexing services

- Maximum visibility for your research

Submit your manuscript at www.biomedcentral.com/submit 